ЕЖОВ Дмитрий Александрович - кандидат политических наук, доцент; доцент департамента политологии факультета социальных наук и массовых коммуникаций Финансового университета при Правительстве РФ (125993, Россия, г. Москва, ГСП-3, Ленинградский пр-кт, 49; president@lenta.ru)

\title{
ИЗБИРАТЕЛЬНОЕ ПРАВО И ИЗБИРАТЕЛЬНЫЙ ПРОЦЕСС В АКТУАЛЬНОМ ПРОЧТЕНИИ
}

\author{
(рецензия на учебное пособие Р.А. Алексеева \\ «Избирательная система, избирательный процесс \\ и технологии»)
}

\begin{abstract}
Аннотация. Статья представляет собой рецензию на учебное пособие Р.А. Алексеева «Избирательная система, избирательный процесс и технологии». Отдельный акцент делается на актуальности контента рецензируемого издания ввиду отражения в нем изменений в избирательном законодательстве, продиктованных условиями пандемии коронавируса COVID-19.

Ключевые слова: избирательная система, избирательный процесс, избирательные технологии, избирательное право, выборы
\end{abstract}

B вышедшем из печати в 2020 г. учебном пособии Р.А. Алексеева «Избирательная система, избирательный процесс и технологии» [Алексеев 2020] обобщаются распространенные в политологической и юридической литературе подходы к трактовке содержания таких понятий, как избирательная система и избирательные технологии; рассматриваются основы избирательного права и процесса. Концептуально контент пособия коррелирует с авторской позицией, изложенной в предыдущих публикациях, в т.ч. в монографии «Избирательная система как фактор становления и развития российской демократии (сравнительное политико-правовое исследование)» [Алексеев 2019], в особенности в части презентации понимания избирательной системы, что свидетельствует о явной интеграции научного знания в реальный образовательный процесс. Подход к изложению материала пособия очевидным образом стимулирует обучающихся к углубленному изучению дисциплины и эффективной самостоятельной работе с дополнительной литературой.

В рецензируемом учебном пособии сделан смысловой акцент на проблемах становления и функционирования избирательной системы в России. При подготовке пособия используются различные методы научного познания, такие как метод правовой и политологической компаративистики, структурнофункциональный подход, эмпирические приемы, позволяющие проанализировать статистические данные различных избирательных кампаний.

Междисциплинарный характер избирательного права и процесса как учебной и научной дисциплины позволил рассмотреть ее основополагающие категории и понятия с различных ракурсов. Не секрет, что тип избирательной системы, избирательный процесс и его стадии, а также виды избирательных технологий оказывают прямое воздействие не только на функционирование политической системы, но и на расстановку политических сил, структуру и порядок образования выборных органов власти и должностных лиц. Данный факт свидетельствует о высокой степени практической значимости пособия.

Учебное пособие имеет логичную структуру, включающую в себя введение, пять глав, заключение и список используемых источников. Каждая глава снабжена контрольными вопросами для проверки усвоения изучаемого материала. 
В первой главе «Понятие, отличительные особенности и виды избирательных систем» конкретизируется понятие избирательной системы и приводятся ее характеристики. Рассматривая избирательную систему в контексте системного подхода, автор пособия видит в ней «политико-правовую целостность, состоящую из таких взаимосвязанных и взаимообусловленных элементов, как избирательное право (источник избирательной системы); избирательный процесс, состоящий из ряда последовательно сменяющих друг друга стадий и предстающий как механизм функционирования избирательной системы; способы определения результатов голосования (результативность избирательной системы)» [Алексеев 2020: 9]. Институт выборов при этом интерпретируется как система подсчета результатов голосования и как характеристика избирательной системы. В главе также последовательно рассматриваются мажоритарные, пропорциональные и смешанные избирательные системы, оцениваются положительные и отрицательные стороны мажоритарных и пропорциональных электоральных формул.

Подводя итоги первой главы, автор отмечает, что «от выбора избирательной системы зависит расстановка политических сил в стране, конфигурация партийной системы, а также порядок образования и структура институтов представительной демократии. Проанализировав способы избрания (виды избирательных систем), можно сделать вывод, что идеальной модели избирательной системы не существует. У каждой из них можно найти как достоинства, так и недостатки. Этим обстоятельством объясняется то великое многообразие избирательных систем, применяемых в современном мире» [Алексеев 2020: 26-27].

Вторая глава «Избирательное право как право граждан на участие в управлении делами государства» посвящена раскрытию понятия, видов и основных принципов избирательного права, вопросу ограничения избирательных прав граждан с помощью избирательных цензов. В процессе изложения материала делается дополнительный акцент на авторском восприятии избирательного права как источника избирательной системы [Алексеев 2020: 28]. В выводах по главе отмечается: «...институт избирательного права, с одной стороны, рассматривается в качестве совокупности норм права, определяющих порядок выборов представительных органов власти и выборных должностных лиц, с другой - выступает правом граждан избирать (активное избирательное право) и быть избранными (пассивное избирательное право) в органы государственной власти и местного самоуправления» [Алексеев 2020: 42].

Третья глава пособия посвящена избирательному процессу, интерпретируемому как механизм реализации избирательного права в государстве, его сущности и основным стадиям. Стадии избирательного процесса рассматриваются и анализируются от даты назначения выборов до подсчета голосов избирателей, участвующих в выборах различного уровня. Отдельное внимание уделяется принципам «нарезки» избирательных округов, процедурам голосования и подведению его результатов.

Своеобразным тематическим переходом к изложению проблематики избирательных технологий является четвертая глава «Электоральное поведение». В ней рассмотрены понятие, виды и модели электорального поведения, отдельное внимание при этом уделяется электоральному абсентеизму. Ввиду взаимозависимости электорального поведения и формата партийной системы интересным представляется подход, предполагающий понимание партийной идентификации как основы электорального выбора, в своем основании, в частности, опирающийся на идеи Й. Шумпетера [Алексеев 2020: 69-71]. Несомненного внимания заслуживает анализ особенностей электорального поведения и активности на президентских и парламентских выборах в России. В выводах по 
главе отмечается, что «электоральное поведение выступает составной частью электорального процесса» [Алексеев 2020: 93]. Существенным для осознания и экспликации специфики электорального поведения в России является то, что российские политологи и социологи, реципировавшие западные классические концепции и теории электорального поведения, приспосабливали их к российским реалиям, что зачастую приводило к неправильной трактовке, однако в настоящее время отечественные ученые предлагают свои концепции электорального поведения, учитывающие специфику российского политического ландшафта [Алексеев 2020: 94].

Заключительная, пятая глава учебного пособия посвящена избирательным технологиям. Автор последовательно обращается к рассмотрению понятия избирательных технологий, требований к ним, подходов к их классификации. Отдельное внимание уделено «черному» $P R$ («грязным» избирательным технологиям). В ходе обобщений, сделанных по итогам главы, отмечается, что «избирательные технологии выступают в качестве способов, средств и приемов, через которые осуществляется воздействие на электоральные предпочтения избирателей, а также как процесс коммуникации между участвующим в выборах кандидатом (партией) и избирателями. Одновременно с этим избирательные технологии выступают в качестве междисциплинарной категории, объединяющей в себе базовые основы различных гуманитарных наук (политология, социология, юриспруденция, психология, маркетинг, экономика, статистика и т.д.)» [Алексеев 2020: 113].

Актуальность контента рецензируемого пособия определяется совокупностью факторов - от динамики функционирования и совершенствования избирательной системы (электоральной формулы), влияющей на порядок замещения постов и должностей (от глав муниципальных образований до главы государства), формирующейся в результате выборов, до расстановки сил в представительных органах власти (от местных до национальных законодательных инстанций). Более того, в условиях процесса демократизации происходит повышение уровня политической и правовой культуры, совершенствование применяемых в избирательных кампаниях избирательных технологий, распространение в целом ряде государств электронного голосования и технологий избирательного блокчейна. Следует отметить, что термин «избирательный блокчейн» введен в научный оборот автором учебного пособия в публикации, подготовленной в соавторстве с А.В. Абрамовым [Алексеев, Абрамов 2020]. В пособии дается целостная характеристика электронного голосования, рассматриваются его положительные и отрицательные стороны.

В результате рассмотрения и анализа мировой и российской практики использования интернет-голосования в целом и одной из его разновидностей - технологии блокчейна в частности отмечается их «универсальность и, как следствие, возможность их применения (в качестве одной из альтернатив традиционному голосованию с помощью бумажных бюллетеней) на выборах различного уровня в России» [Алексеев 2020: 60]. С точки зрения автора пособия, данные виды дистанционного голосования позволят осуществить волеизъявление избирателям, которые в связи с ограничением в передвижении по состоянию здоровья, нахождением за границей, в силу занятости и иных причин предпочитают проголосовать вне стен избирательного участка [Алексеев 2020: 60].

Немаловажным фактом, характеризующим своевременность рецензируемого учебного пособия, является учет его автором новаций в избирательном законодательстве, появившихся в 2020 г. В частности, указывается: «В 2020 г. (в связи с пандемией COVID-19) были внесены поправки в российское избирательное законодательство, позволяющие проводить выборы в течение нескольких дней 
(в совокупности не более трех), данное решение должно приниматься соответствующей избирательной комиссией. С 2020 г. было узаконено голосование по почте и дистанционное электронное голосование на выборах всех уровней» [Алексеев 2020: 51-52]. По состоянию на момент выхода из печати пособия подобное упоминание фактически является первым в учебной литературе.

В целом учебное пособие характеризуется наличием представленного в нем видения эволюции избирательной системы, избирательного процесса и избирательных технологий, отвечающего современным научным представлениям. Оно может быть рекомендовано для студентов, обучающихся по гуманитарным специальностям, членов избирательных комиссий, политологов и политических технологов, занимающихся освещением и организационно-техническим обеспечением выборов, юристов, занимающихся изучением проблем избирательного права и избирательного законодательства, а также самой широкой аудитории, интересующейся особенностями избирательного процесса в России и зарубежных странах.

\section{Список литературы}

Алексеев Р.А. 2019. Избирательная система как фактор становления и развития российской демократии (сравнительное политико-правовое исследование). М.: ИНФРА-М. 211 с.

Алексеев Р.А. 2020. Избирательная система, избирательный процесс и технологии: учебное пособие. М.: ИИУ МГОУ. 136 с.

Алексеев Р.А., Абрамов А.В. 2020. Проблемы и перспективы применения электронного голосования и технологии избирательного блокчейна в России и за рубежом. - Гражданин. Выборы. Власть. № 1(15). С. 9-21.

EZHOV Dmitriy Aleksandrovich, Cand.Sci. (Pol.Sci.), Associate Professor; Associate Professor of the Department of Political Science, Faculty of Social Sciences and Mass Communications, Financial University under the Government of the Russian Federation (49 Leningradsky Ave, GSP-3, Moscow, Russia, 125993; president@lenta.ru)

\section{ELECTORAL LAW AND ELECTORAL PROCESS IN THE ACTUAL READING (review of the textbook «Electoral System, Electoral Process and Technologies», written by R.A. Alekseev)}

Abstract. The article is a review of the textbook «Electoral System, Electoral Process and Technologies», written by R.A. Alekseev. Special emphasis is placed on the relevance of the content of the peer-reviewed publication due to its reflection of changes in the electoral legislation dictated by conditions of the COVID-19 coronavirus pandemic.

Keywords: electoral system, electoral process, electoral technologies, electoral law, elections 